\title{
Inferência da Temperatura Interna em uma Incubadora Neonatal Utilizando Redes Neurais Artificiais
}

\author{
Joilane S. Rocha ${ }^{1}$, Yasmin M.Perci ${ }^{1}$, Gabryel F. Soares ${ }^{1}$, José M. A. Júnior ${ }^{1}$ \\ ${ }^{1}$ Departamento de Engenharia Elétrica - Universidade Federal do Piauí (UFPI) \\ CEP: 64049-550 - Teresina - PI - Brasil \\ joilaner86@gmail.com, yasperci@gmail.com, gabryelfigl8@gmail.com, \\ jmjunior@ufpi.edu.br
}

\begin{abstract}
The neonatal incubator is a hospital equipment that provides suitable temperature conditions for newborns. This work proposes a neural inference system, based on Artificial Neural Networks (ANN) of the MultiLayer Perceptron (MLP) type, which will be used as a virtual sensor. This system will replace the installation of physical sensors during the certification or maintenance of the incubator and will be possible to monitore temperature online. The results demonstrated that the neural inference system can be used satisfactorily as a virtual sensor. Mean quadratic validation errors between $1.6 \times 10^{-3}$ and $1.9 \times 10$ ${ }^{-3}$ and variance between $2.533 \times 10^{-7}$ and $8,098 \times 10^{-7}$ were obtained.
\end{abstract}

Resumo. A incubadora neonatal consiste em um equipamento hospitalar que proporciona condições de temperatura adequadas aos recém-nascidos. Este trabalho propõe um sistema de inferência neural, obtido a partir de redes neurais artificiais (RNA) do tipo MultiLayer Perceptron (MLP), que será utilizado como sensor virtual. Esse sistema substitui a instalação de sensores físicos durante a certificação ou manutenção da incubadora e tornará possivel a realização do monitoramento on-line da temperatura. Os resultados demonstraram que o sistema pode ser utilizado satisfatoriamente como sensor virtual. Foram obtidos erros médios quadráticos de validação entre $1.6 \times 10^{-3}$ e $1.9 \times 10^{-3}$ e variância entre $2.533 \times 10^{-7}$ e $8.098 \times 10^{-7}$.

\section{Introdução}

De acordo com o [IBGE 2019], estima-se que a mortalidade infantil no Brasil foi de 12.35 mortes por mil nascidos vivos para o ano de 2018. A principal causa está relacionada à hipotermia, que ocorre quando a temperatura do recém-nascido (RN) passa a ser inferior a $36.5^{\circ} \mathrm{C}$. Diversos fatores ambientais contribuem com a hipotermia: baixa temperatura na sala de parto, transporte neonatal e controle inadequado do ambiente térmico.

Para o controle da hipotermia na vida extrauterina, utiliza-se a incubadora neonatal, na qual a temperatura do recém-nascido é regulada e monitorada de forma eficiente. Sendo assim, as incubadoras foram desenvolvidas para possibilitar aos recém-nascidos condições ambientais ideais para quando o mesmo estiver em dificuldade de adaptação com o meio externo.

Por serem muito sensíveis às alterações ambientais, é preciso certificar constantemente a incubadora, verificando se os valores de temperatura no interior de sua cúpula estão dentro de faixas de operação estabelecidas pela 
norma técnica NBR IEC (International Electrotechnical Commission) 60601-2-19 [Associação Brasileira de Normas Técnicas 2014]. Caso essas temperaturas não estejam dentro dos limites estabelecidos pela norma, deve ser executada a manutenção da incubadora. Para isto, são realizados vários testes, nos quais sensores físicos são inseridos em seu interior, sendo necessário retirar a incubadora de operação [de Araújo et al. 2013].

Existem diversos trabalhos na literatura voltados para o desenvolvimento de técnicas de otimização do funcionamento das incubadoras. O trabalho [Santos and Braga 2016], apresenta a identificação do sistema de uma incubadora neonatal baseada em técnicas adaptativas e um modelo de rede neural artificial (RNA). Dentre os modelos propostos, ARMA, RNA, ARMAX-RNA, este último se mostrou o mais promissor, com menor desvio padrão em todos os experimentos realizados. O trabalho de [de Araújo et al. 2013], propõe um novo procedimento de inferência baseado em redes neurais, com o objetivo de avaliar e calibrar a temperatura e umidade de uma incubadora neonatal. Para isso, foram apresentadas as vantagens obtidas desde a redução do número de sensores até a eficácia do método empregado, que alcançou baixos valores de erros em relação aos valores reais.

Como pode ser visto nos trabalhos mencionados, todos eles utilizam redes neurais artificiais aplicadas em incubadoras neonatais. As redes neurais artificiais consistem de técnicas computacionais inspiradas na estrutura do cérebro, sendo uma das ferramentas mais difundidas e estudadas na literatura [Souza 2018].

À vista disso, a proposta desta pesquisa é desenvolver sensores virtuais, por meio de um sistema de inferência, com aplicação em tempo real e que faz uso de uma RNA do tipo MLP, treinada com base na estrutura Neural Network with Finite Inpulse Response (NNFIR). Os sensores virtuais propostos serão capazes de substituir os sensores físicos nos pontos especificados na norma NBR IEC 60601-2-19, evitando, assim, a retirada do neonato da incubadora para realização de medições necessárias aos procedimentos de certificação e manutenção, permitindo o aumento do tempo de utilização do equipamento.

O sistema proposto realizará a inferência dos valores de temperatura no interior da cúpula da incubadora por meio da utilização de variáveis secundarias: temperaturas medidas por um sensor externo e por um sensor que fica na estrutura interna da incubadora, próximo ao resistor de aquecimento. Espera-se que os valores de temperatura inferidos por meio da RNA sejam satisfatoriamente próximos aos valores medidos através dos sensores físicos posicionados nos pontos determinados pela norma, possibilitando o uso efetivo dessa estrutura como sensor virtual.

\section{Incubadora Neonatal}

A incubadora neonatal é um equipamento médico - assistencial destinado a gerar e manter um ambiente ideal para a manutenção da vida do recém-nascido, permitindo um desenvolvimento mais saudável do neonato com baixo peso, prematuro ou com outras disfunções que justifiquem sua utilização [de Oliveira Filho et al. 2018], [Agostini et al. 2003].

O modelo de incubadora neonatal utilizado no presente trabalho é SCTI LINE. Nele, a parte que fica abaixo da cúpula corresponde ao compartimento onde ficam presentes um motor, resistência e sensores de temperatura e circulação de ar. O motor tem a função de impulsionar o ar para o compartimento do recém-nascido (RN), levando o calor 
e umidade ao paciente. Os sensores de temperatura e circulação de ar são responsáveis pela leitura da temperatura do ar e alarmes de segurança da incubadora. A aquisição de dados, proveniente desses sensores e o controle do aquecimento da incubadora neonatal são realizados por meio de uma placa microprocessada. $\mathrm{O}$ hardware utilizado possui comunicação via USB com o computador para recepção de comandos e envio dos dados medidos.

Apesar de a incubadora ter fixo em sua estrutura um sensor de temperatura, o mesmo não é utilizado durante procedimentos de certificação e manutenção. Para a realização dos procedimentos citados, cinco sensores físicos de temperatura são inseridos no interior da cúpula, conforme orienta a norma IEC 60601-2-19. Essa norma especifica que esses sensores adicionais devem ser colocados em cinco pontos, A à D e M, a uma distância de 10 centímetros do colchão. $\mathrm{O}$ ponto $\mathrm{M}$ deve estar no centro, como mostra a Figura 1. Os demais pontos devem estar no centro das quatro áreas formadas pelas linhas que dividem tanto a altura quanto a largura do colchão.

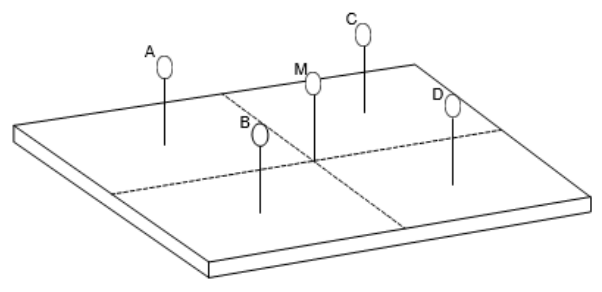

Figura 1. Posição dos sensores conforme a ABNT NBR IEC 60601-2-19

\section{Rede Neural Artificial}

Redes neurais artificiais se configuram como uma técnica que possui a capacidade de aprendizado e adaptação, características essas que são copiadas do funcionamento de sistemas neurais biológicos [Vellasco 2017]. Para alcançarem um bom desempenho, as redes neurais empregam uma interligação maciça de células computacionais simples denominadas neurônios ou unidades de processamento [Haykin 2007].

Um dos tipos mais comuns de RNAs são as redes MLP, que tem estrutura formada por uma camada de entrada, pelo menos uma camada intermediária (também denominada de camada escondida) e uma camada de saída [Nied 2007]. Trata-se de uma rede classificada como supervisionada, visto que seu processo de aprendizagem tem como base dados de entrada-saída e ajusta os seus parâmetros de modo iterativo através desses dados e do sinal de erro.

O treinamento da RNA pode ser realizado por meio do algoritmo backpropagation, que é constituído de duas etapas. Na primeira, chamada forward, um padrão de entrada é apresentado à RNA e seu efeito é propagado, camada a camada, até produzir um conjunto de saídas. Na segunda etapa, conhecida como backward, são calculadas as derivadas da função do erro com respeito aos pesos da RNA. O fluxo dos sinais nesta etapa é propagado da camada de saída para a camada de entrada [Haykin 2007]. Deve-se destacar que na etapa forward, os pesos sinápticos são mantidos fixos, enquanto na etapa backward os pesos são ajustados. 
Na Figura 2 é apresentado um exemplo da arquitetura da rede MLP, onde é possível verificar o fluxo de dados na rede. As entradas da rede $\left(x_{i}\right)$ e o bias $(+1)$ são multiplicados pelos pesos sinápticos $\left(w_{i j}\right.$ e $\left.W_{i j}\right)$, no qual são utilizadas como entradas das funções de ativação $\left(f_{a i}\right)$ presentes na camada oculta. Em seguida, as saídas dessas funções são ponderadas por pesos sinápticos $\left(W_{i j}\right)$, sendo aplicado no calculo das funções de ativação dos neurônios presentes na camada de saída, obtendo-se, por fim, a resposta da rede neural $\left(z_{i}\right)$. Nesse caso, especificamente, a rede possui três entradas com dois neurônios na camada oculta e dois neurônios na camada de saída. A equação (1) mostra matematicamente o cálculo da saída da RNA para uma única camada escondida.

$$
z_{i}(k, \theta)=f a_{i}\left[\sum_{j=1}^{n_{2}} W_{i j} f a_{j}\left(\sum_{l=1}^{n_{1}} W_{j l} x_{l}+w_{j 0}\right)+w i_{0}\right]
$$

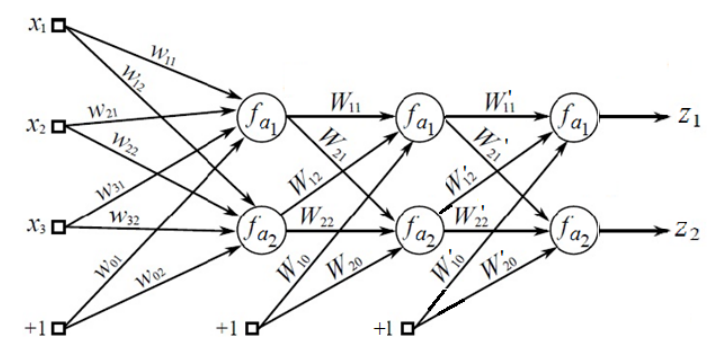

Figura 2. Perceptron de Múltiplas Camadas - MLP

Alguns parâmetros devem ser definidos para a implementação de uma RNA, como por exemplo, o tipo de função de ativação, onde as mais populares são: logística, linear, gaussiana e tangente hiperbólica. Outro componente é a taxa de aprendizagem, pois de acordo com a definição do seu valor, é alcançada a estabilidade e uma adequada convergência do processo de aprendizagem [Haykin et al. 2009]. Por fim, o critério de parada pode ser definido por meio da quantidade de épocas ou um valor predeterminado uma função custo, que pode ser representada pelo erro médio quadrático (EMQ), calculado a partir da diferença entre a saída da rede neural e o valor desejado para cada exemplos de treinamento, conforme Equação (2).

$$
E M Q=\frac{1}{N} \sum_{k=1}^{N}(y-\widehat{y})^{2}
$$

\subsection{Estruturas de Modelagem}

As estruturas baseadas em redes neurais apropriadas para identificação de sistemas nãolineares são generalizações das estruturas de modelagem linear (FIR, ARX, ARMAX, etc). Para este trabalho, utilizou-se a estrutura Neural Network FIR (NNFIR) que é um vetor de regressão formado apenas por medições passadas das variáveis de entrada do processo a ser identificado [Nørgård et al. 2000].

A estrutura de modelagem NNFIR é descrita pela Equação (3):

$$
\widehat{y}(k+d)=\varphi^{T}(k, d, n) * \theta
$$


onde $\widehat{y}(\mathrm{k}+\mathrm{d})$ corresponde à saída estimada pelo modelo, $\varphi^{T}$ representa o vetor de regressão do modelo NNFIR formado por valores passados da variável de entrada do processo, $d$ simboliza o atraso da planta, $k$ é o instante atual, $n$ é a ordem da planta e $\theta$ é o vetor de parâmetros. $\mathrm{O}$ vetor de regressão da estrutura NNFIR se torna a entrada da rede neural, de modo a se obter a estimativa da saída de $\widehat{y}(k)$.

\subsection{Sistemas de Inferência}

Sistemas de inferência são algoritmos matemáticos capazes de estimar, em tempo real, variáveis de interesse (variáveis primárias), a partir de outras variáveis disponíveis (variáveis secundárias). Esses sistemas vêm adquirindo grande aplicabilidade devido às vantagens que apresentam frente a alguns problemas de medição dos sensores reais [Araújo Júnior 2007].

Esses modelos inferenciais, quando aplicados em tempo real são definidos como sensores virtuais. O desenvolvimento dos modelos inferenciais possibilita o conhecimento de variáveis importantes do processo a partir de outras variáveis facilmente medidas, tais como temperatura, pressão, vazão, e outras [Ito 2014].

Vale ressaltar que, os sensores virtuais surgiram no mercado com o intuito de estimar em tempo real a variável desejada a partir de dados obtidos na planta, no qual esses sensores podem ser considerados como o resultado da intersecção da tecnologia de Sensores Inteligentes e das técnicas de Modelagem e Identificação de Sistemas [Lotufo and Garcia 2008]. Assim, o sensor virtual advém da associação de um sensor (hardware), que permite medições on-line de algumas variáveis do processo com um algoritmo de estimação (software), a fim de prover estimativas de variáveis não medidas, parâmetros do modelo ou superar atrasos de medições [de Assis and Maciel Filho 2000].

\section{Metodologia}

De início, foram definidas as variáveis de entrada para o treinamento da rede neural, sendo escolhidas a temperatura interna, medida próxima ao resistor de aquecimento, e a temperatura externa (correspondente ao ambiente onde se encontra a incubadora). Sendo assim, estas são as variáveis secundárias. Em seguida, determinou-se as variáveis correspondentes a saída da rede neural (temperaturas nos pontos A, B, C, D e M). Para obtenção dos dados relativos à temperatura interna, aplicou-se no resistor de aquecimento um sinal de excitação do tipo Pseudo Sequência Binária Aleatória (PRBS) [Tulleken 1990].

O período de amostragem adotado para a realização da coleta de dados para treinamento e validação foi de 60 segundos, resultando em 318 amostras. Após a realização dessa coleta, foi feita a montagem do vetor de regressão a ser utilizado como entrada da rede neural. Como já dito anteriormente, a rede neural implementada no presente trabalho foi a MLP, sendo treinada tendo como base a estrutura de modelagem NNFIR e implementada no software Matlab.

A estrutura NNFIR, se caracteriza por um vetor de regressão contendo valores presentes e passados do sinal de entrada do sistema. No entanto, como a rede neural está sendo aplicada como um sistema de inferência, o vetor de regressão foi construído com os valores medidos pelo sensor presente na cúpula (temperatura interna, $T_{i} n t$ ), além do valor medido pelo sensor de temperatura externa $\left(T_{e} x t\right)$, ou seja, as variáveis secundárias. 
Portanto, a partir dessas variáveis, a rede neural deverá inferir os valores das temperaturas nos pontos A, B, C, D e M, como apresentado na Figura 3.

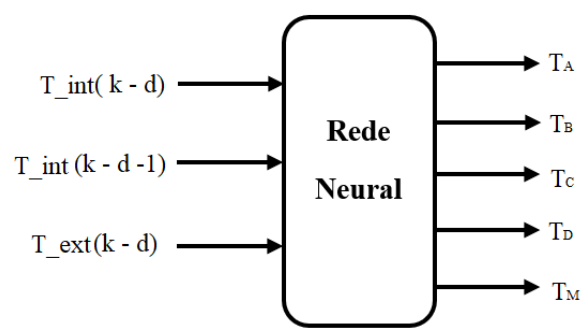

Figura 3. Estrutura de treinamento das redes para temperatura

Antes de efetuar o treinamento da rede, foram realizados testes, variando-se os parâmetros da mesma, tais como a quantidade de amostras para treinamento e validação, função de ativação, coeficiente de aprendizagem, número de neurônios na camada oculta e de épocas, a fim de se encontrar uma configuração que apresentasse resultados mais satisfatórios, proporcionando o menor erro médio quadrático possível, assim como a variância. Dessa forma, a melhor configuração encontrada apresentou uma arquitetura com 3 entradas, 12 neurônios na camada escondida, com número máximo de épocas de treinamento igual a 200.000 épocas.

\section{Resultados}

Após a realização de testes iniciais, foram definidas 247 amostras para treinamento e 70 amostras para teste. No treinamento da rede MLP, utilizou-se a função de ativação do tipo logística ou sigmoide, tanto na camada oculta quanto para a camada de saída. O coeficiente de aprendizagem, $\eta$, mais adequado foi de 0,1 .

Após essas definições, foi realizado o treinamento da rede neural para cada um dos cinco pontos cujas temperaturas devem ser inferidas. Os resultados relativos ao Erro Médio Quadrático, Média e Variância desses treinamentos estão apresentados na Tabela 1. Vale ressaltar que, para obter os valores de média e variância o treinamento da rede foi repetido dez vezes.

Tabela 1. Erro médio quadrático de validação para cada sensor

\begin{tabular}{|c|c|c|c|}
\hline Sensor & EMQ de Validação & Média do EMQ & Variância do EMQ $\left(\mathbf{x 1 0}^{-7}\right)$ \\
\hline A & 0.0018 & 0.00309 & 8.098 \\
\hline B & 0.0019 & 0.00282 & 6.440 \\
\hline M & 0.0016 & 0.00261 & 6.519 \\
\hline C & 0.0018 & 0.00260 & 2.533 \\
\hline D & 0.0016 & 0.00238 & 3.351 \\
\hline
\end{tabular}

Como pode ser visto na Tabela 1, os erros médio quadrático de validação ficaram próximos de zero, apresentando valores entre $1.6 \times 10^{-3}$ e $1.9 \times 10^{-3}$. No entanto, para os valores de média do EMQ e variância, observa-se que o ponto A apresentou os maiores valores, tanto de média do EMQ quanto de variância, em comparação com os demais pontos. Os valores apresentados pela rede neste ponto foram de 0.00309 e $8.098 \times 10^{-7}$, 
respectivamente. Mesmo assim, o desempenho pode ser considerado satisfatório. Além disso, nota-se também que o ponto D apresenta a menor média para o EMQ e o segundo menor valor para a variância, com valores de 0.00238 e $3.351 \times 10^{-7}$, respectivamente.

A seguir, na Figura 4 , são apresentados gráficos com os sinais de saída da rede neural comparados com a saída desejada para os sensores localizados nos pontos A, B, $\mathrm{M}, \mathrm{C}$ e D, respectivamente.
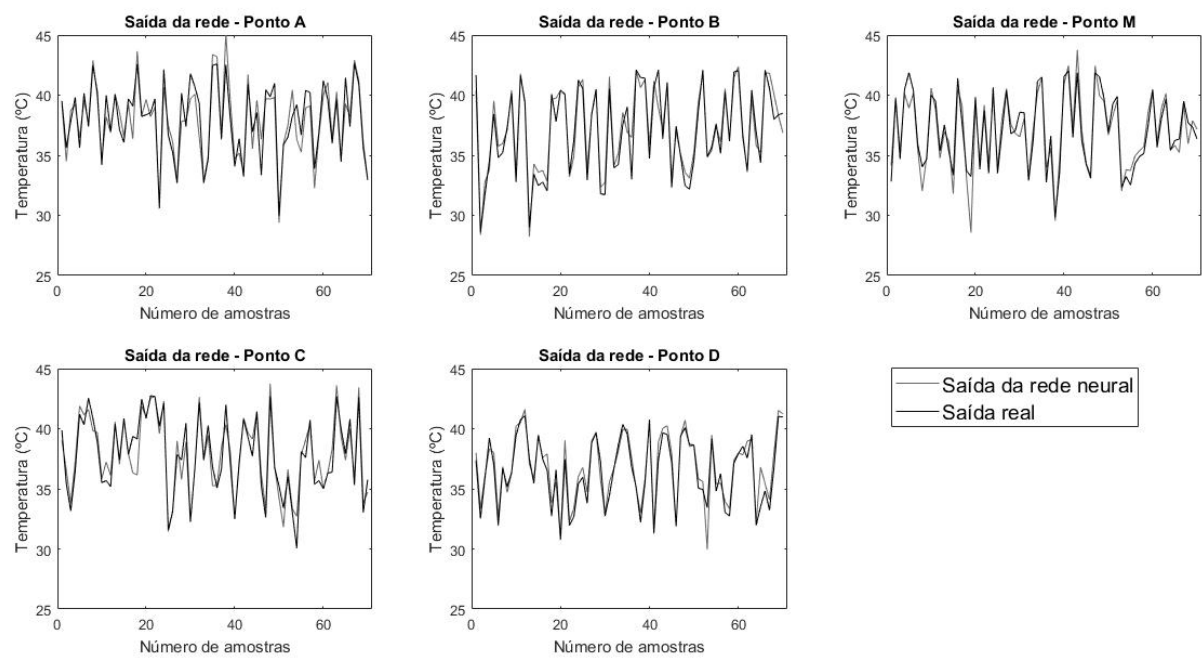

Figura 4. Comparação entre a saída da MLP e os valores reais

$\mathrm{Na}$ figura 4, é possível concluir que as curvas correspondentes as respostas da rede neural se aproximaram de forma adequada das respostas desejadas em todas as faixas de operação. No geral, é possível constatar que os valores relacionados aos erros apresentados na Tabela 1 ficaram entre uma faixa de valores parecidos, e que a saída estimada pela rede foi muito próxima à saída real, demonstrando que o sistema de inferência é capaz de estimar satisfatoriamente as temperaturas nos cinco pontos definidos pela norma IEC 60601-2-19, podendo ser utilizado como sensor virtual.

\section{Conclusão}

A incubadora neonatal é um equipamento essencial em unidades de terapia intensiva e, por lidar com pacientes muito sensíveis às mudanças ambientais, deve ser constantemente certificada. O objetivo do trabalho foi desenvolver um conjunto de 5 sensores virtuais por meio de redes neurais artificiais, com base no modelo NNFIR, capazes de inferir as temperaturas nos cinco pontos exigidos pela norma. Os valores de temperatura obtidos com a rede neural MLP foram suficientemente próximos dos valores reais, demonstrando que foi possível modelar a dinâmica do sistema com relação as temperaturas nos pontos determinados pela norma IEC 60601-2-19. O desenvolvimento dos sensores virtuais permitirá que a medição da temperatura para fins de procedimentos de certificação e manutenção seja feita sem a necessidade de se adicionar sensores físicos, sem interromper o funcionamento da incubadora neonatal. Como sugestão de trabalhos futuros, pode ser realizada a inferência da umidade, bem como a comparação com outros modelos de redes neurais. 


\section{Referências}

Agostini, N. et al. (2003). Sistema computadorizado para verificação da funcionalidade em incubadoras neonatais.

Araújo Júnior, J. M. d. (2007). Técnicas de inteligência artificial para a geração dinâmica de set points para uma coluna de destilação. Master's thesis, Universidade Federal do Rio Grande do Norte.

Associação Brasileira de Normas Técnicas (2014). ABNT NBR IEC 60601-2-19:2014 Equipamento eletromédico Parte 2-19: Requisitos particulares para segurança básica e desempenho essencial das incubadoras para recém-nascidos. Versão corrigida da ABNT NBR IEC 60601-2-19:2014 incorpora a Errata 2, de 05.05.2017. Esta Norma foi confirmada em virtude da publicação da Emenda 1 de 10.07.2019.

de Araújo, J. M., De Menezes, J. M. P., Moura de Albuquerque, A. A., Da Mota Almeida, O., and Ugulino de Araújo, F. M. (2013). Assessment and certification of neonatal incubator sensors through an inferential neural network. Sensors, 13(11):15613-15632.

de Assis, A. J. and Maciel Filho, R. (2000). Soft sensors development for on-line bioreactor state estimation. Computers \& Chemical Engineering, 24(2-7):1099-1103.

de Oliveira Filho, J. I., da Mota Almeida, O., and de Araújo, J. M. (2018). Desenvolvimento de hardware para a medição de parâmetros de temperatura e umidade em uma incubadora neonatal. Revista Principia - Divulgação Científica e Tecnológica do IFPB, $1: 121$.

Haykin, S. (2007). Redes neurais: princípios e prática. Bookman Editora.

Haykin, S. S. et al. (2009). Neural networks and learning machines/simon haykin.

IBGE (2019). Síntese de Indicadores Sociais - SIS.

Ito, E. H. (2014). Desenvolvimento de um sensor virtual de composição em coluna de destilação para aplicação em tempo real.

Lotufo, F. A. and Garcia, C. (2008). Sensores virtuais ou soft sensors: Uma introdução. Brazilian Conference on Dynamics, Control and Applications.

Nied, A. (2007). Treinamento de redes neurais artificiais baseado em sistemas de estrutura variável com taxa de aprendizado adaptativa.

Nørgård, P. M., Ravn, O., Poulsen, N. K., and Hansen, L. K. (2000). Neural networks for modelling and control of dynamic systems-a practitioner's handbook.

Santos, N. and Braga, A. (2016). Técnicas adaptativas, armax, rna e armax-rna, na identificação de sistemas de uma incubadora neonatal. pages 1-8.

Souza, F. R. d. L. (2018). Identificação e controle de sistemas dinâmicos utilizando uma fuzzy wavelet neural network. Master's thesis, Brasil.

Tulleken, H. J. (1990). Generalized binary noise test-signal concept for improved identification-experiment design. Automatica, 26(1):37-49.

Vellasco, M. (2017). Redes neurais artificiais. 2007. Laboratório Computacional Aplicada-PUC/RJ. Apostila. PDF. Disponível em: http://www2. ica. ele. pucrio. br/Downloads\% 5C33/ICA-introdu\% C3\% A7\% C3\% A3o\% 20RNs. pdf, 9(05). 